\title{
Long-distance feedback projections to area V1: Implications for multisensory integration, spatial awareness, and visual consciousness
}

\author{
SIMON CLAVAGNIER, ARNAUD FALCHIER, and HENRY KENNEDY \\ Université Claude Bernard Lyon 1, Bron, France
}

\begin{abstract}
It is generally agreed that information flow through the cortex is constrained by a hierarchical architecture. Recent experimental evidence suggests that projections descending the hierarchy and targeting the primary visual cortex (area V1) may play an essential role in perceptual processes. We have, therefore, reexamined feedback projections to area V1, using retrograde tracer injections in this area. In addition to well-known areas, quantification of labeling in higher cortical areas reveals a number of hitherto unknown long-distance feedback connections originating from auditory (A1), multisensory (STP) cortices, but also from a perirhinal area (36). These feedback projections from advanced cortical stations, a global feature shared by areas that belong to the ventral visual stream, could play an important role in early multisensory integration and spatial awareness and could provide the physical substrate for the involvement of area V1 in visual consciousness.
\end{abstract}

Understanding how the cerebral cortex processes information is a major aim of neurobiology today, with important implications for disciplines ranging from psychiatry to the designing of living machines. Numerous investigative techniques at different levels are used to this end, including functional brain imaging, single-unit recording, and anatomy. These techniques rapidly converge at the level of the cortical area, where specific physiological functions can be localized and each area exhibits distinct patterns of connectivity. The concerted action of multiple areas is thought to underlie sensory processes and cognitive functions. This has led to a major field of research that attempts to determine the position of individual areas in the overall cortical organization of information flow. Work in the visual system has been particularly fruitful in this respect. Here, Hubel and Wiesel in the 1970s built on a tradition going back to Hughlings Jackson, which conceived that the brain was structured along hierarchical principals. In Hubel and Wiesel's work, hierarchical relations were explored, and it was shown, for example, that as one progresses from the primary area (area V1) to successively higher areas (V2, V3, V4, etc.) there is a progressive increase in both the dimensions and

This work was supported by EU Grant "Nets and Representations" QLG3-1999-0106, Human Frontier Science Program Grant RG0133/ 2000-B, and European Community FP5 Quality of Life Grant QLG31999-01064, A.F. was supported by the Fondation pour la Recherche Médicale. We thank Colette Dehay, Marie-Thérèse Perenin, and Charlie Schroeder for their critical comments on an earlier version of the article. We are grateful to Souhila Benkerri and Delphine Autran for their histological processing and to Delphine Autran for data analysis. Correspondence concerning this article should be addressed to $\mathrm{H}$. Kennedy, INSERM U371, Cerveau et Vision, IFR 19 Institut Fédératif des Neurosciences de Lyon, INSERM U371, 18 Avenue Doyen Lépine, 69675 Bron Cedex, France (e-mail: kennedy@lyon.inserm.fr). the complexity of receptive fields. This approach led to the concept that different attributes of the retinal image, such as color and movement, are emphasized in different areas (Zeki, 1978). In this way, information is thought to be extracted at the successive levels going from lower to higher visual areas according to a feedforward direction.

Physiological investigation of the cortex has recently put into question this feedforward hypothesis of information flow, and it is becoming increasingly clear that feedback processes need to be considered as well. One major issue is that the timing of activation of successive levels simply does not fit with the concept of strictly sequential activation (Petroni, Panzeri, Hilgetag, Kotter, \& Young, 2001). Intracranial recording in the monkey has shown that there is considerable overlap in the timing of the signal response at successive hierarchical stages (Nowak, Munk, James, Girard, \& Bullier, 1999; Raiguel, Lagae, Gulyas, \& Orban, 1989; Schmolesky et al., 1998; Zipser, Lamme, \& Schiller, 1996). Furthermore, there is experimental evidence of rapid widespread activation of the sensory parietal cortex within $45 \mathrm{msec}$ and of prefrontal areas within $90 \mathrm{msec}$ (Foxe \& Simpson, 2002; Juan \& Walsh, 2003). Together, these studies have shown that fast activation of higher areas, coupled with late activation of area $\mathrm{V} 1$, means that V1 can have a higher area function, which in turn could generate the known attentional processes in early visual areas including the primary visual cortex (Allman, Miezin, \& McGuinness, 1985; Kastner \& Ungerleider, 2000; Mehta, Ulbert, \& Schroeder, 2000a, 2000b; Motter, 1993; Somers, Dale, Seiffert, \& Tootell, 1999; Vanduffel, Tootell, \& Orban, 2000). Temporal, but also spatial, attributes of activity in response to a stimulus point to the higher function of area V1. There is increasing evidence that area V1 neurons are influenced by stimuli outside of the classical receptive field, leading to complex 
contextual responses (Nothdurft, Gallant, \& Van Essen, 1999; Zipser et al., 1996). These long-range interactions beyond the receptive field clearly fit with the high divergence of feedback projections from higher areas (Angelucci et al., 2002; Kennedy \& Bullier, 1985; Salin, Girard, Kennedy, \& Bullier, 1992). Furthermore, these feedback projections originating from sensory nonvisual areas provide the basis for multisensory integration (Falchier, Clavagnier, Barone, \& Kennedy, 2002).

Multisensory integration of sensory inputs has been shown to occur at multiple sites, including midbrain and cortical levels (Stein \& Meredith, 1993). Multisensory convergence is not a sufficient condition for multisensory integration. At the level of a single neuron, the convergence of inputs from different sensory modalities often, but not always (Wallace \& Stein, 1994), results in the integration of concurrent signals, so that responses are significantly different from those obtained with either of the modality-specific components alone (Stein \& Meredith, 1993). Classical descriptions of the visual cortex predict an integration of visual and nonvisual stimuli at later stages of cortical processing (Calvert, Brammer, \& Iversen, 1998; Hikosaka, Iwai, Saito, \& Tanaka, 1988). Most anatomical and electrophysiological studies have pointed to multisensory convergence in areas located in the temporal, parietal, and frontal cortex (Benevento, Fallon, Davis, \& Rezak, 1977; Goldman-Rakic, 1988). However there is recent electrophysiological and brain-imaging evidence that visual, auditory, and somatosensory integration occurs at relatively early stages of the visual cortical pathways (Giard \& Peronnet, 1999; Macaluso, Frith, $\&$ Driver, 2000). Recent imaging studies performed on humans have shown cortical multisensory integration sites early in visual pathways and especially around the lingual gyrus, where early visual areas are located (Macaluso et al., 2000). This result is also supported by fMRI studies showing multisensory integration in the region of the superior occipital gyrus (Calvert, Hansen, Iversen, \& Brammer, 2001). These findings in favor of early multisensory integration were unexpected because anatomical studies of the monkey brain failed until recently to detect afferent connections to the primary visual cortex from areas processing modalities other than vision. This stands in contrast with evidence that congenital blindness leads to the responding by early visual cortical areas in the dorsal stream to nonvisual stimuli, including auditory stimuli (Weeks et al., 2000) and tactile stimuli in a discrimination task (Buchel, Price, Frackowiak, \& Friston, 1998; Cohen et al., 1999; Sadato et al., 1996). It is thought that these nonvisual responses are being relayed back to early visual cortical stages via feedback projections from the parietal cortex (Pons, 1996). However, we need to keep in mind that nonvisual information may have access to the visual areas through rewiring of subthalamic pathways during development (Angelucci, Clasca, \& Sur, 1998).

The primary visual area V1 of the primate contains a fine-grain map of the visual world and receives the bulk of ascending visual pathways (Zeki, 1993). It also receives a large number of cortico-cortical connections, which have been described as largely from visual cortical areas (Barone, Batardière, Knoblauch, \& Kennedy, 2000; Felleman \& Van Essen, 1991; Perkel, Bullier, \& Kennedy, 1986). Weak afferent projections to V1 have been described from distant areas in the ventral (TEO, TE) and dorsal (MST, LIP) pathways (Barone et al., 2000; Felleman \& Van Essen, 1991; Perkel, et al., 1986; Rockland, 1994). All these areas respond principally to visual and oculomotor stimuli, except for the LIP, where auditory-related activity has been reported (Linden, Grunewald, \& Andersen, 1999).

Jones and Powell (1970) have postulated that the connectivity of primary sensory areas is restricted to those areas of the same modality. The evidence in favor of multisensory convergence at the first cortical stage of information processing has prompted us to challenge the concept put forward by Jones and Powell concerning the definition of a primary area.

\section{METHOD}

In order to establish the complete pattern of cortical connectivity of area V1, we implemented a quantitative analysis using tracers of optimal sensitivity. We made injections of the retrograde tracers fast blue and diamidino yellow in area V1 subserving central and peripheral visual fields. A major property of these tracers is that they give very clear injection sites, with highly restricted pickup zones (Bullier, Kennedy, \& Salinger, 1984). These tracers are extremely sensitive, and counting the number of neurons in different areas and layers makes it possible to determine two parameters (Figures 1 and 2): (1) the FLN which refers to the fraction of labeled neurons in each area and indicates the relative contribution of a given connection (Falchier et al., 2002; Vezoli et al., in press,); and (2) the SLN, which indicates the hierarchical distance separating the labeled area from the injected area (Barone et al., 2000). Four retrograde tracing experiments were carried out on 3 cynomolgus monkeys (Macaca fascicularis). Some of the results from these injections have already been reported in another article (Falchier et al., 2002). Central area 17 injections were in the cortex subserving $0^{\circ}-2^{\circ}$ in the lower visual field (M85RHDY and M85RHFsB). Injections aimed at the peripheral representation were made in the head and stem of the calcarine sulcus by means of vertical penetrations, using stereotaxic coordinates. Two different eccentricities can be distinguished in peripheral area 17 injections. The M76LH injection was located in the dorsal leaf of the calcarine cortex subserving $10^{\circ}-12^{\circ}$ eccentricity (Falchier et al., 2002). The other peripheral injection (M81RH) was located further ventrally, near the junction of the dorsal leaf with the calcarine stem, and were in the cortex subserving $15^{\circ}-20^{\circ}$. A detailed explanation of the histological procedures has been reported elsewhere (Falchier et al., 2002).

Immunohistochemical and myelin staining criteria made it possible to localize labeled neurons in MT, MST, FST (STS complex), STP, and auditory areas (Cusick, 1997; Morel, Garraghty, \& Kaas, 1993). The auditory area A1, located in the posterior bank of the lateral sulcus, is distinguished by using acetylcholynesterase and cytochrome oxidase reactivity (Morel et al., 1993) and by the presence of a strong parvalbumin staining in Layers 2-4 (Kosaki, Hashikawa, He, \& Jones, 1997). The perirhinal and parahippocampal cortices were delimitated using SMI-32 staining and the Nissl method for cytoarchitectonic analysis (Suzuki \& Amaral, 2003). 


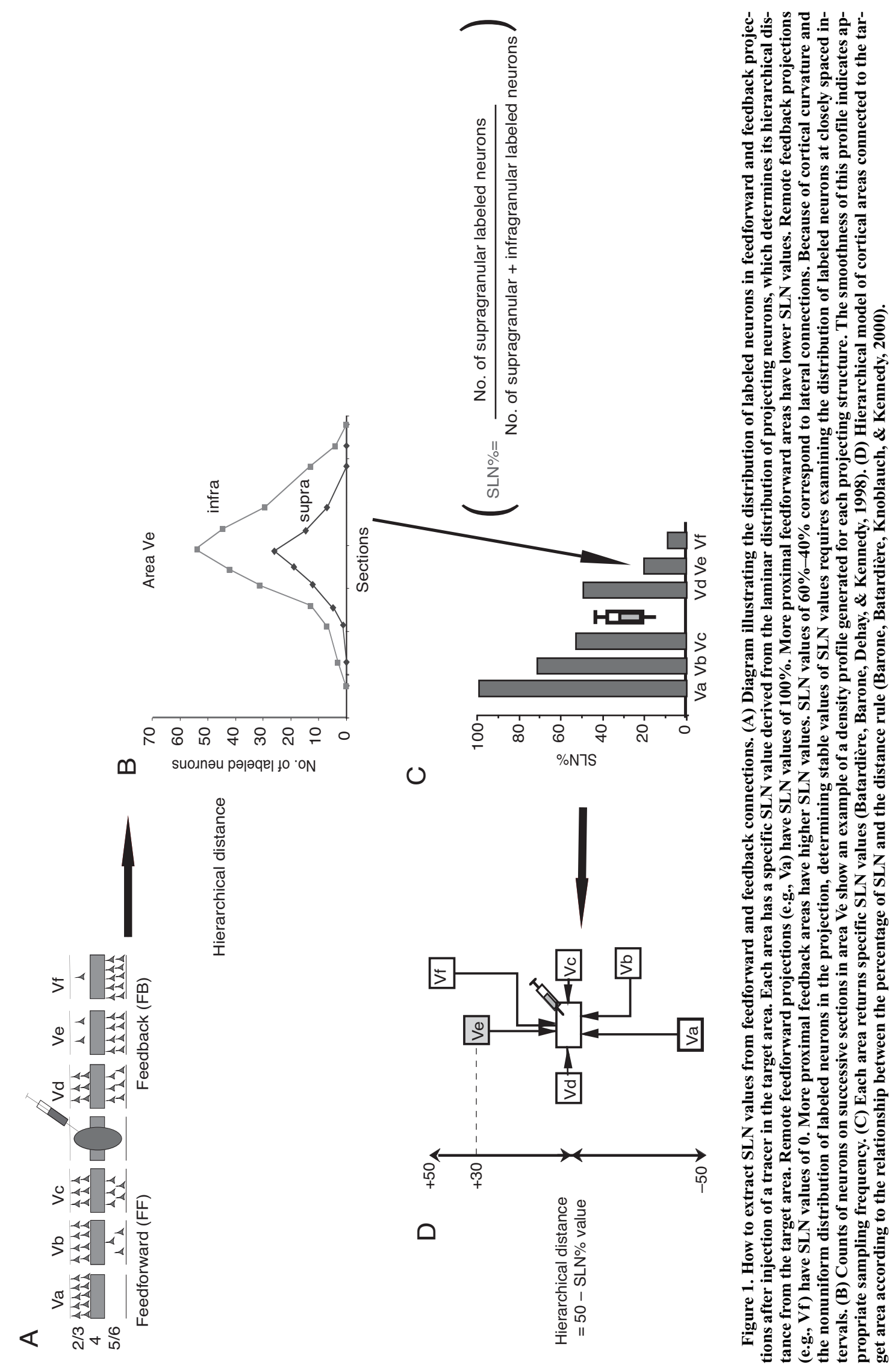


A
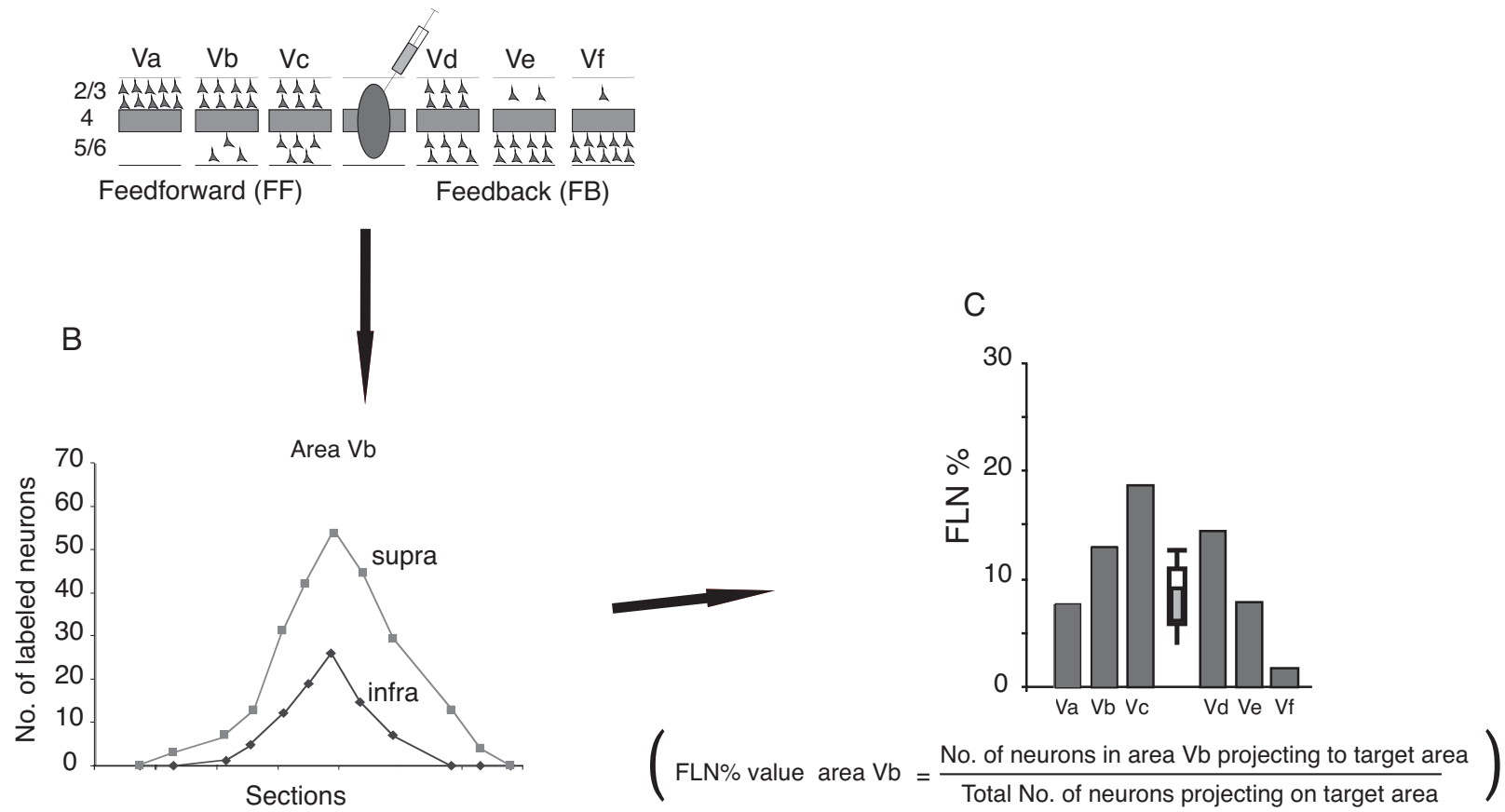

Figure 2. Extraction of FLN values from feedforward and feedback connections. (A) and (B) same as those in Figure 1. (C) Adapted sampling frequency allows us to calculate precisely the total number of projecting neurons for each area. This makes it possible to determine the relative contribution of each area to the total afferent connectivity of the target area.

\section{RESULTS}

Labeled neurons were found in the 13 cortical areas that are known to provide projections to area V1, including the recently described projection from STP and A1 (Falchier et al., 2002; Rockland \& Ojima, 2003). Labeled neurons were found in the medial temporal lobe in accordance with earlier reports (Doty, 1983; Kennedy \& Bullier,

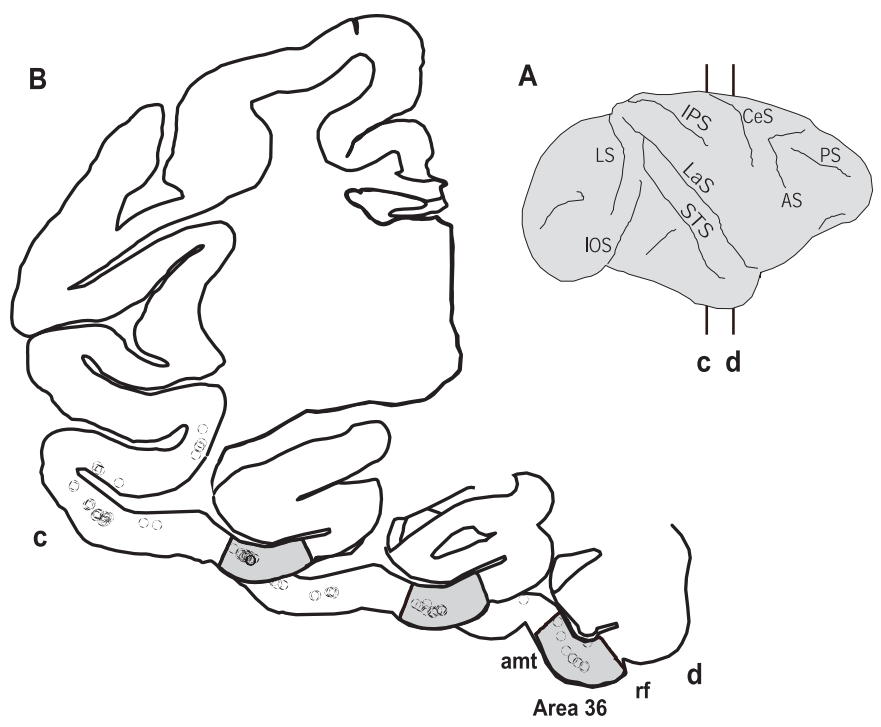

Figure 3. Labeling in area 36 after V1 injections. (A) Lateral view of the brain and vertical sections showing levels of sections $c$ and $d$. (B) Individual sections showing labeling in the temporal cortex. Shaded regions represent the extent of the cortex in which labeled neurons were considered to be in area 36 between the amt sulcus (amt) and the rhinal fissure (rf). 
1985; Lyon \& Kaas, 2002; Rockland \& Van Hoesen, 1994). An unexpected finding was the presence of labeled neurons in area 36 (Figure 3). Preliminary FLN data suggest that projections from $\mathrm{TH}$ and $\mathrm{TF}$ to area $\mathrm{V} 1$ are comparable in strength to the projections originating from STP and A1.

We have used the SLN values to construct a hierarchical model of the relationships of the areas showing long distance projections to area V1 (Figure 4).

We have also indicated, on the Felleman and Van Essen (1991) model of the visual cortex, those areas that show long-distance feedback connections to area V1 (Figure 5). This reveals that all of the so-called ventral stream areas have long-distance connections with area V1.

\section{DISCUSSION}

The present results show that area $\mathrm{V} 1$ receives projections from a number of areas that have classically not been considered to be part of the visual system. After making interspecies comparisons, we shall consider the feedback projections from STP and the auditory cortices with respect to multisensory convergence and spatial awareness. Our results also reveal long-distance feedback projections to area V1 from areas located at the top of the Felleman and Van Essen (1991) hierarchical model (area $36, \mathrm{TH}$, and TF). These pathways are discussed with regard to their possible involvement in visual imagery.

\section{Interspecies Comparison}

Although sparse projections from the primary auditory cortex to area V2 in adult rodents and cats have been reported (Innocenti, Berbel, \& Clarke, 1988; Miller \& Vogt, 1984), such projections to area V1 are thought to be absent in these species (Dehay, Kennedy, \& Bullier, 1988; Montero, 1993; Sanderson, Dreher, \& Gayer, 1991; Symonds \& Rosenquist, 1984). Although we cannot exclude the possibility that some of the studies above might have missed an auditory projection to peripheral area V1, Montero and colleagues have specifically addressed this issue and have found no such projection (Montero, 1993). Furthermore, although a direct projection from the auditory cortex to area V1 has been reported in the opossum, it is considerably weaker than that to area V2 (Martinich, Pontes, \& Rocha-Miranda, 2000). These interspecies comparisons suggest that the projection of the auditory cortex and the STP to peripheral area V1 might be a unique primate feature. However it needs to be remembered that homologies of the STP in nonprimates are difficult to identify.

\section{Feedback Projections and Multisensory Integration}

Schroeder has argued that multisensory convergence at early stages indicates a high-order function at lowlevel sensory cortices, which is compatible with reverse hierarchy theory (Cauller, 1995; Hochstein \& Ahissar, 2002; Schroeder et al., 2003). The auditory system is organized in parallel streams. The caudal parabelt (which contains $70 \%$ of the neurons of the auditory cortices projecting to area V1) is part of the dorsal auditory pathway specialized in spatial information processing, including sound source localization (Kaas \& Hackett, 2000; Recanzone, 2000; Tian, Reser, Durham, Kustov, \& Rauschecker, 2001). Overall, the auditory cortex plays an important role in sound localization, and receptive fields are large and extend behind the pinna axis (Barone, Clarey, Irons, \& Imig, 1996). Similarly, auditory receptive fields in the STP are large and expand in the peripheral visual field (Hikosaka et al., 1988). Hence, there is a certain degree of

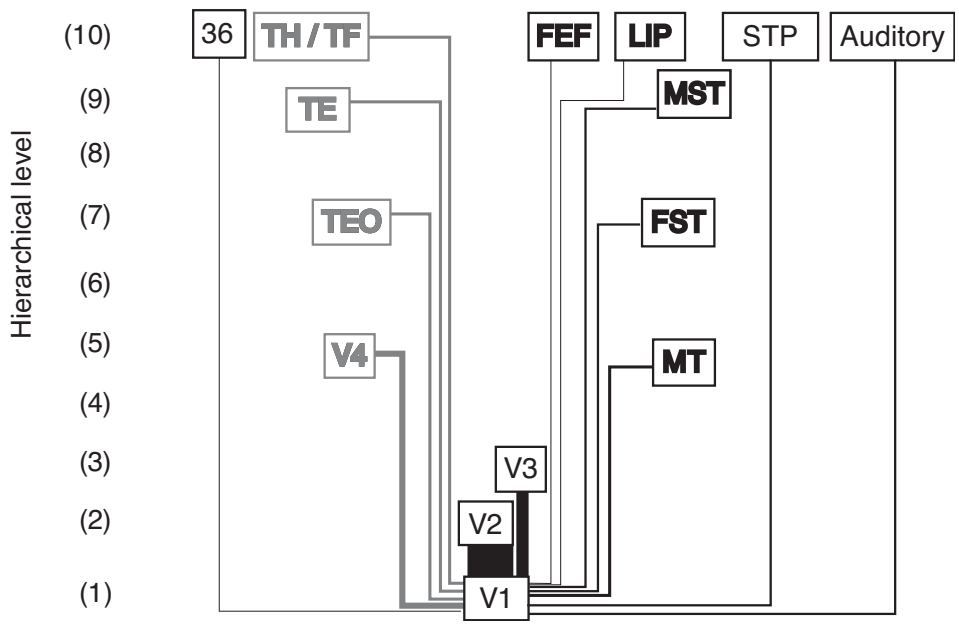

Figure 4. Direct feedback connections to area V1. The hierarchical distance is calculated using the SLN values (Barone, Batardière, Knoblauch, \& Kennedy, 2000). The thickness of the lines indicates the strength of the connection obtained by FLN values (Falchier, Clavagnier, Barone, \& Kennedy, 2002; Vezoli et al., in press). Areas in black, dorsal stream; gray, ventral stream. 


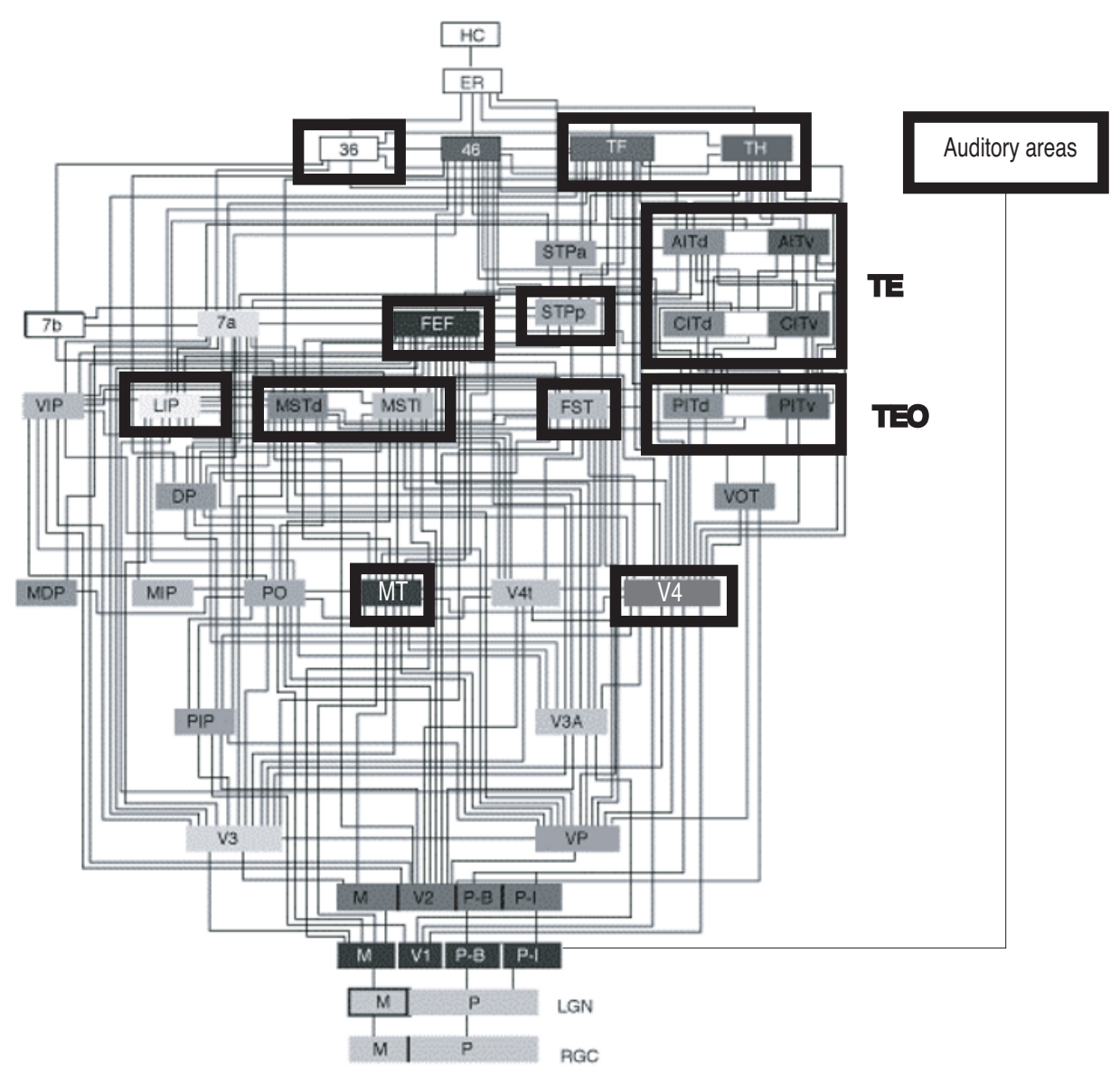

Figure 5. The modified hierarchical model of Felleman and Van Essen (1991). Areas beyond area V3A showing long-distance feedback projections to area V1 are outlined.

spatial congruence in the auditory properties of A1/STP and the visual representation of the part of area V1 to which these areas project.

Multisensory integration serves to enhance perceptual capacities (Stein \& Meredith, 1993), so that, for example, the addition of an auditory signal to a visual stimulus might lead to improved detection and reduced delay and, therefore, an improved orientation response, as compared with visual stimuli alone (Giard \& Peronnet, 1999; Goldring, Dorris, Corneil, Ballantyne, \& Munoz, 1996; McDonald, Teder-Salejarvi, \& Hillyard, 2000). This is relevant to our findings because the short latencies to auditory stimulus in A1 and the STP (Bruce, Desimone, \& Gross, 1981; Recanzone, Guard, \& Phan, 2000; Schroeder $\&$ Foxe, 2002) mean that the projections from these areas to V1 could participate in a foveation mechanism toward a peripheral sound source (Heffner \& Heffner, 1992). Recently, a new form of multisensory convergence has been reported (Dehner, Keniston, Clemo, \& Meredith, 2004). The authors provided evidence of auditory suppression of somatosensory responses in area SIV in the cat. Such a mechanism may play a role in cross-modal selective attention, whereby attention to one modality broadly sup- presses activity in another. Since no auditory responses have yet been reported in V1 neurons, one can speculate that such a type of interaction might exist in the primary visual area.

Multisensory integration can play an important role in the functional reorganization of the cortex following sensory deprivation. This could be made possible by cortical pathways such as the auditory/STP projection to peripheral area V1 (Pons, 1996). In patients suffering from early blindness, early visual areas, including the primary visual cortex, are responsive to tactile (Buchel et al., 1998; Cohen et al., 1999; Sadato et al., 1996) and auditory (Weeks et al., 2000) stimuli. The functional reorganization in the multisensory area observed after early visual deprivation (Rauschecker, 1995; Wanet-Defalque et al., 1988; Yaka, Yinon, \& Wollberg, 1999) might be coupled to a functional strengthening of the auditory and STP connections to V1 by overtraining in the nonaffected modalities.

Peripheral visual deafferentation in the newborn cat induces an improvement in spatial auditory localization performances later in life (Korte \& Rauschecker, 1993; Rauschecker \& Kniepert, 1994) that has been explained by cortical compensatory mechanisms in the multisensory 
areas (Rauschecker \& Korte, 1993). This could have important behavioral consequences, such as the improved capacity of the blind to localize sound in peripheral auditory space (Roder et al., 1999). A recent PET study also has shown auditory activation of V1 and V2 in postlingually deaf subjects implanted with cochlear implants, listening to sounds with closed eyes (Giraud, Price, Graham, Truy, $\&$ Frackowiak, 2001). These authors have suggested that the activation of the visual cortex is similar to the recruitment of the auditory cortex during speech reading (Calvert et al., 1997). One can assume that cross-modal cooperation could compensate for the subthreshold stimulation by processing complementary information from another sensory modality. Hence, anatomical, electrophysiological, and brain-imaging studies support a model of cross-modal integration within a distributed network of cortical areas in which the primary visual area could participate in the initial integration of sensory information (Calvert, Campbell, \& Brammer, 2000; Stein, 1998). Cross-modal integration has a particular importance for theories of visual consciousness, which we shall examine in the next section.

\section{Feedback Projections and Visual Consciousness}

Cortico-cortical feedforward projections going from lower to higher hierarchical levels are thought to elaborate receptive field responses (Bullier, Girard, \& Salin, 1994; Vanduffel, Payne, Lomber, \& Orban, 1997; Zeki, 1993). Feedback mechanisms play a role in integrating information outside of the classical receptive field and figure-ground discrimination (Hupé et al., 1998; Lamme \& Roelfsema, 2000). Such top-down influences could provide the substrate of high-level effects, such as selective attention in area V1 (Kastner \& Ungerleider, 2000; Lamme \& Roelfsema, 2000; Mehta et al., 2000a, 2000b). Recent experiments have directly addressed the possible role of feedback projections in the visual consciousness. Pascual-Leone and Walsh (2001) showed that stimulation of V5 elicits moving phosphenes, which disappear during inactivation of area V1. The work of Logothetis has examined neuronal response coding perception and responses to the retinal image at different cortical stages. Using binocular rivalry and an adaptation paradigm, this work has shown that at early cortical stations, there are some neurons that change activity according to the percept, and not the retinal image, and hence, strongly supports the idea of top-down processes (Leopold \& Logothetis, 1996; Tolias, Smirnakis, Augath, Trinath, \& Logothetis, 2001).

\section{Feedback Projections and Visual Imagery}

Feedback pathways have also been implicated in visual imagery (Miyashita, 1995). There is a large body of evidence that visual imagery activates early cortical stages, including area $\mathrm{V} 1$, again indicating top-down processes (Thompson \& Kosslyn, 2000). Cross-modal activity can be associated with the mental image of the stimuli and has been implicated in the activation of the calcarine cortex in humans (Klein, Paradis, Poline, Kosslyn, \& Le Bihan, 2000). Similarly, in humans performing a tactile object recognition task, tactile-specific activity has been observed in the calcarine visual cortex in the absence of visual information (Deibert, Kraut, Kremen, \& Hart, 1999).

It is still debated whether mental images are fundamentally different from verbal thoughts, whether they share common mechanisms with visual perception, and whether information in images is represented in a maplike, spatial format. But most neuropsychological, psychophysical, and neuroimaging studies have indicated that visual perception and mental imagery share common mechanisms (Farah, 1995; Ishai \& Sagi, 1995; Miyashita, 1995; but see Bartolomeo, 2002).

Furthermore, visual imagery activates several visual regions, including area V1 (for a review, see Kosslyn, Ganis, \& Thompson, 2001). By recording single neurons in the human medial temporal lobe while subjects were asked to imagine previously viewed images, Kreiman, Koch, and Fried (2000) showed that single neurons in the hippocampus, amygdala, entorhinal cortex, and parahippocampal gyrus selectively altered their firing rates, depending on the nature of the imaginary stimulus. In this respect, the connections we report between parahippocampal areas $\mathrm{TH} / \mathrm{TF}$ and perirhinal area 36 and $\mathrm{V} 1$, as well as the connections from the amygdala to V1 (Amaral, Behniea, \& Kelly, 2003), could constitute the pathway that activates and modulates area V1 during visual recall (memory and imagery). According to the theories of reverse hierarchy and visual imagery, the activation of area V1 is specifically required for fine-grain visual images (Hochstein \& Ahissar, 2002; Kosslyn et al., 2001).
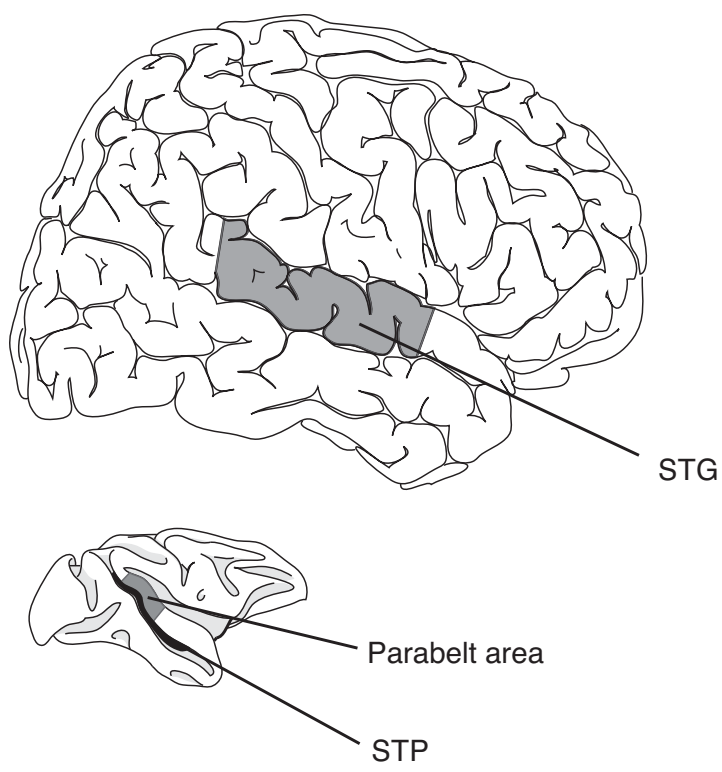

$1 \mathrm{~cm}$

Figure 6. Unilateral neglect in the human and the monkey. This figure shows the regions in the human and the monkey brain where lesions result in unilateral neglect. In the monkey brain, the parabelt area is in gray, and the STP is in black. The sulci are unfolded in the monkey brain. 


\section{Feedback Projections and Spatial Awareness}

Lesions of the STP and surrounding areas in the superior temporal gyrus (presumably, the parabelt) in the monkey were found to induce deficits strongly resembling unilateral neglect in human (Luh, Butter, \& Buchtel, 1986; Watson, Valenstein, Day, \& Heilman, 1994). Although there is still some debate about the exact site of the lesion that generates this syndrome in the human, a recent study has put forward a strong argument in favor of the STG (Karnath, Ferber, \& Himmelbach, 2001; see Figure 6). Patients with unilateral neglect typically behave as if the left part of their visual field or even of their own body no longer exists (Bisiach \& Vallar, 1988). This syndrome can be defined as a spatial awareness disorder because it is not restricted to the visual modality but includes tactile and auditory modalities (Karnath \& Perenin, 1998; Pavani, Làdavas, \& Driver, 2003). Could it be that the involvement of the STP in the monkey in spatial awareness is related to the fact that the STP, a multisensory cortical area (Cusick, 1997), has direct feedback projections to area V1?

\section{CONCLUSION}

In the present article, we have developed the proposition that feedback projections to area V1 play an important role in spatial and visual cognition. An important aspect of this concept, which needs to be further explored, is that the cognitive function of area V1 is linked in some way to the multisensory convergence that occurs at this level. Furthermore, multisensory convergence at each hierarchical step of each sensory system may be a necessary feature for building a unified conscious system. Future work is required to explore whether a similar anatomical basis exist for multisensory integration in the primary cortices of other sensory modalities.

\section{REFERENCES}

Allman, J., Miezin, R., \& McGuinness, E. (1985). Stimulus specific responses from beyond the classical receptive field: Neurophysiological mechanisms for local-global comparisons in visual neurons. Annual Review of Neuroscience, 8, 407-430.

Amaral, D. G., Behniea, H., \& Kelly, J. L. (2003). Topographic organization of projections from the amygdala to the visual cortex in the macaque monkey. Neuroscience, 118, 1099-1120.

Angelucci, A., Clasca, F., \& Sur, M. (1998). Brainstem inputs to the ferret medial geniculate nucleus and the effect of early deafferentation on novel retinal projections to the auditory thalamus. Journal of Comparative Neurology, 400, 417-439.

Angelucci, A., LevitT, J. B., Walton, E. J., Hupe, J. M., Bullier, J., \& LUND, J. S. (2002). Circuits for local and global signal integration in primary visual cortex. Journal of Neuroscience, 22, 8633-8646.

Barone, P., Batardière, A., Knoblauch, K., \& Kennedy, H. (2000). Laminar distribution of neurons in extrastriate areas projecting to visual areas V1 and V4 correlates with the hierarchical rank and indicates the operation of a distance rule. Journal of Neuroscience, 20 , 3263-3281.

Barone, P., Clarey, J. C., Irons, W. A., \& Imig, T. J. (1996). Cortical synthesis of azimuth-sensitive single-unit responses with nonmonotonic level tuning: A thalamocortical comparison in the cat. Journal of Neurophysiology, 75, 1206-1220.
Bartolomeo, P. (2002). The relationship between visual perception and visual mental imagery: A reappraisal of the neuropsychological evidence. Cortex, 38, 357-378.

Batardière, A., Barone, P., Dehay, C., \& Kennedy, H. (1998). Areaspecific laminar distribution of cortical feedback neurons projecting to cat area 17: Quantitative analysis in the adult and during ontogeny. Journal of Comparative Neurology, 396, 493-510.

Benevento, L. A., Fallon, J., Davis, B. J., \& Rezak, M. (1977). Auditory-visual interaction in single cells in the cortex of the superior temporal sulcus and the orbital frontal cortex of the macaque monkey. Experimental Neurology, 57, 849-872.

Bisiach, E. V., \& Vallar, G. (1988). Hemineglect in humans. In F. Boller \& J. Grafman (Eds.), Handbook of Neuropsychology (Vol. 1, pp. 195-222). Amsterdam: Elsevier.

Bruce, C., Desimone, R., \& Gross, C. G. (1981). Visual properties of neurons in a polysensory area in superior temporal sulcus of the macaque. Journal of Neurophysiology, 46, 369-384.

Buchel, C., Price, C., Frackowiak, R. S., \& Friston, K. (1998). Different activation patterns in the visual cortex of late and congenitally blind subjects. Brain, 121 (Pt. 3), 409-419.

Bullier, J., Girard, P., \& Salin, P. A. (1994). The role of area 17 in the transfer of information to extrastriate visual cortex. In A. Peters \& K. S. Rockland (Eds.), Primary visual cortex in primates (Vol. 10, pp. 301-330). New York: Plenum.

Bullier, J., Kennedy, H., \& SAlinger, W. (1984). Branching and laminar origin of projections between visual cortical areas in the cat. Journal of Comparative Neurology, 228, 329-341.

Calvert, G. A., Brammer, M. J., \& Iversen, S. D. (1998). Crossmodal identification. Trends in Cognitive Sciences, 7, 287-253.

Calvert, G. A., Bullmore, E. T., Brammer, M. J., Campbell, R., Williams, S. C. R., McGuire, P. K.,Woodruff, P. W. R., Iversen, S. D., \& DAvid, A. S. (1997). Activation of auditory cortex during silent lipreading. Science, 276, 593-596.

Calvert, G. A., Campbell, R., \& Brammer, M. J. (2000). Evidence from functional magnetic resonance imaging of crossmodal binding in the human heteromodal cortex. Current Biology, 10, 649-657.

Calvert, G. A., Hansen, P. C., Iversen, S. D., \& Brammer, M. J. (2001). Detection of audio-visual integration sites in humans by application of electrophysiological criteria to the BOLD effect. NeuroImage, 14, 427-438.

CAULLER, L. (1995). Layer I of primary sensory neocortex: Where topdown converges upon bottom-up. Behavioural Brain Research, 71, 163-170.

Cohen, L. G., Weeks, R. A., SAdato, N., Celnik, P., Ishit, K., \& HalLETT, M. (1999). Period of susceptibility for cross-modal plasticity in the blind. Annals of Neurology, 45, 451-460.

Cusick, C. G. (1997). The superior temporal polysensory region in monkeys. In E. G. Jones \& A. Peters (Eds.), Cerebral cortex (Vol. 12, pp. 435-468). New York: Plenum.

Dehay, C., Kennedy, H., \& Bullier, J. (1988). Characterization of transient cortical projections from auditory, somatosensory, and motor cortices to visual areas 17, 18, and 19 in the kitten. Journal of Comparative Neurology, 272, 68-89.

Dehner, L. R., Keniston, L. P., Clemo, H. R., \& Meredith, M. A. (2004). Cross-modal circuitry between auditory and somatosensory areas of the cat anterior ectosylvian sulcal cortex: A "new" inhibitory form of multisensory convergence. Cerebral Cortex, 14, 387-403.

Deibert, E., Kraut, M., Kremen, S., \& Hart, J., Jr. (1999). Neural pathways in tactile object recognition. Neurology, 52, 1413-1417.

Doty, R. W. (1983). Nongeniculate afferents to striate cortex in macaques. Journal of Comparative Neurology, 218, 159-173.

Falchier, A., Clavagnier, S., Barone, P., \& Kennedy, H. (2002). Anatomical evidence of multimodal integration in primate striate cortex. Journal of Neuroscience, 22, 5749-5759.

FARAH, J. M. (1995). The neural bases of mental imagery. In M. S. Gazzaniga (Ed.), The cognitive neurosciences (pp. 963-974). Cambridge, MA: MIT Press.

Felleman, D. J., \& Van Essen, D. C. (1991). Distributed hierarchical processing in the primate cerebral cortex. Cerebral Cortex, 1, 1-47.

FoXe, J. J., \& Simpson, G. V. (2002). Flow of activation from V1 to 
frontal cortex in humans: A framework for defining "early" visual processing. Experimental Brain Research, 142, 139-150.

Giard, M. H., \& PERONNET, F. (1999). Auditory-visual integration during multimodal object recognition in humans: A behavioral and electrophysiological study. Journal of Cognitive Neuroscience, 11, 473-490.

Giraud, A. L., Price, C. J., Graham, J. M., Truy, E., \& FrackowIAK, R. S. (2001). Cross-modal plasticity underpins language recovery after cochlear implantation. Neuron, 30, 657-663.

Goldman-RAKIC, P. S. (1988). Topography of cognition: Parallel distributed networks in primate association cortex. Annual Review of Neuroscience, 11, 137-156.

Goldring, J. E., Dorris, M. C., Corneil, B. D., Ballantyne, P. A., \& Munoz, D. P. (1996). Combined eye-head gaze shifts to visual and auditory targets in humans. Experimental Brain Research, 111, 68-78.

HeFFner, R. S., \& HeFFner, H. E. (1992). Visual factors in sound localization in mammals. Journal of Comparative Neurology, 317, 219-232.

Hikosaka, K., Iwai, E., Saito, H., \& Tanaka, K. (1988). Polysensory properties of neurons in the anterior bank of the caudal superior temporal sulcus of the macaque monkey. Journal of Neurophysiology, 60, 1615-1637.

Hochstein, S., \& Ahissar, M. (2002). View from the top: Hierarchies and reverse hierarchies in the visual system. Neuron, 36, 791-804.

Hupé, J. M., James, A. C., Payne, B. R., Lomber, S. G., Girard, P., \& Bullier, J. (1998). Cortical feedback improves discrimination between figure and background by V1, V2 and V3 neurons. Nature, 394, 784-787.

InNOCENTI, G. M., Berbel, P., \& Clarke, S. (1988). Development of projections from auditory to visual areas in the cat. Journal of Comparative Neurology, 272, 242-259.

IsHAI, A., \& SAGI, D. (1995). Common mechanisms of visual imagery and perception. Science, 268, 1772-1774.

JoNES, E. G., \& PowELL, T. P. (1970). An anatomical study of converging sensory pathways within the cerebral cortex of the monkey. Brain, 93, 793-820.

JUAN, C. H., \& WALSH, V. (2003). Feedback to V1: A reverse hierarchy in vision. Experimental Brain Research, 150, 259-263.

KAAS, J. H., \& HACKETT, T. A. (2000). Sub divisions of auditory cortex and processing streams in primates. Proceedings of the National Academy of Sciences, 97, 11793-11799.

Karnath, H. O., Ferber, S., \& Himmelbach, M. (2001). Spatial awareness is a function of the temporal not the posterior parietal lobe. $\mathrm{Na}$ ture, 411, 950-953.

KARNATH, H. O., \& Perenin, M. T. (1998). Tactile exploration of peripersonal space in patients with neglect. NeuroReport, 9, 22732277.

Kastner, S., \& Ungerleider, L. G. (2000). Mechanisms of visual attention in the human cortex. Annual Review of Neuroscience, $\mathbf{2 3}_{2}$ 315-341.

KENNEDY, H., \& Bullier, J. (1985). A double-labeling investigation of the afferent connectivity to cortical areas V1 and V2 of the macaque monkey. Journal of Neuroscience, 5, 2815-2830.

Klein, I., PARadis, A. L., Poline, J. B., Kosslyn, S. M., \& Le Bihan, D. (2000). Transient activity in the human calcarine cortex during visualmental imagery: An event-related fMRI study. Journal of Cognitive Neuroscience, 12(Suppl. 2), 15-23.

Korte, M., \& RAuscheCKer, J. P. (1993). Auditory spatial tuning of cortical neurons is sharpened in cats with early blindness. Journal of Neurophysiology, 70, 1717-1721.

Kosaki, H., Hashik AWA, T., He, J., \& Jones, E. G. (1997). Tonotopic organization of auditory cortical fields delineated by parvalbumin immunoreactivity in macaque monkeys. Journal of Comparative Neurology, 386, 304-316.

KossLyn, S. M., Ganis, G., \& Thompson, W. L. (2001). Neural foundations of imagery. Nature Reviews Neuroscience, 2, 635-642.

Kreiman, G., Koch, C., \& Fried, I. (2000). Imagery neurons in the human brain. Nature, 408, 357-361.

LAMME, V. A., \& RoELFSEMA, P. R. (2000). The distinct modes of vision offered by feedforward and recurrent processing. Trends in Neurosciences, 23, 571-579.
LEOPOLD, D. A., \& Logothetis, N. K. (1996). Activity changes in early visual cortex reflect monkeys' percepts during binocular rivalry. $\mathrm{Na}$ ture, 379, 549-553.

LiNdEN, J. F., Grunewald, A., \& ANDERSEN, R. A. (1999). Responses to auditory stimuli in macaque lateral intraparietal area:. II. Behavioral modulation. Journal of Neurophysiology, 82, 343-358.

Luh, K. E., ButTer, C. M., \& BuChtel, H. A. (1986). Impairments in orienting to visual stimuli in monkeys following unilateral lesions of the superior sulcal polysensory cortex. Neuropsychologia, 24, 461470.

LyON, D. C., \& KAAS, J. H. (2002). Evidence from V1 connections for both dorsal and ventral subdivisions of $\mathrm{V} 3$ in three species of New World monkeys. Journal of Comparative Neurology, 449, 281-297.

Macaluso, E., Frith, C. D., \& Driver, J. (2000). Modulation of human visual cortex by crossmodal spatial attention. Science, 289, 12061208.

Martinich, S., Pontes, M. N., \& Rocha-Miranda, C. E. (2000). Patterns of corticocortical, corticotectal, and commissural connections in the opossum visual cortex. Journal of Comparative Neurology, 416, 224-244.

McDonald, J. J., Teder-Salejarvi, W. A., \& Hillyard, S. A. (2000). Involuntary orienting to sound improves visual perception. Nature, 407, 906-908.

MeHTA, A. D., Ulbert, I., \& Schroeder, C. E. (2000a). Intermodal selective attention in monkeys: I: Distribution and timing of effects across visual areas. Cerebral Cortex, 10, 343-358.

Mehta, A. D., Ulbert, I., \& Schroeder, C. E. (2000b). Intermodal selective attention in monkeys: II: Physiological mechanisms of modulation. Cerebral Cortex, 10, 359-370.

Miller, M. W., \& Vogt, B. A. (1984). Direct connections of rat visual cortex with sensory, motor, and association cortices. Journal of Comparative Neurology, 226, 184-202.

MiYASHITA, Y. (1995). How the brain creates imagery: Projection to primary visual cortex. Science, 268, 1719-1720.

Montero, V. M. (1993). Retinotopy of cortical connections between the striate cortex and extrastriate visual areas in the rat. Experimental Brain Research, 94, 1-15.

MOREL, A., GarraghTY, P. E., \& KaAs, J. H. (1993). Tonotopic organization, architectonic fields, and connections of auditory cortex in macaque monkeys. Journal of Comparative Neurology, 335, 437459.

MotTer, B. C. (1993). Focal attention produces spatially selective processing in visual cortical areas V1, V2, and V4 in the presence of competing stimuli. Journal of Neurophysiology, 70, 909-919.

Nothdurft, H. C., Gallant, J. L., \& Van Essen, D. C. (1999). Response modulation by texture surround in primate area V1: Correlates of "popout" under anesthesia. Visual Neuroscience, 16, 15-34.

NowaK, L. G., MunK, M. H., James, A. C., Girard, P., \& Bullier, J. (1999). Cross-correlation study of the temporal interactions between areas V1 and V2 of the macaque monkey. Journal of Neurophysiology, 81, 1057-1074.

PaScUAL-LeONe, A., \& WALSh, V. (2001). Fast backprojections from the motion to the primary visual area necessary for visual awareness. Science, 292, 510-512.

PaVANI, F., LÀDAVAS, E., \& Driver, J. (2003). Auditory and multisensory aspects of visuospatial neglect. Trends in Cognitive Sciences, $\mathbf{7}_{2}$ 407-414

Perkel, D. J., Bullier, J., \& Kennedy, H. (1986). Topography of the afferent connectivity of area 17 in the macaque monkey: A doublelabeling study. Journal of Comparative Neurology, 253, 374-402.

Petroni, F., Panzeri, S., Hilgetag, C. C., Kotter, R., \& Young, M. P. (2001). Simultaneity of responses in a hierarchical visual network. NeuroReport, 12, 2753-2759.

Pons, T. (1996). Novel sensations in the congenitally blind. Nature, 380, 479-480.

Raiguel, S. E., Lagae, L., Gulyas, B., \& Orban, G. A. (1989). Response latencies of visual cells in macaque areas V1, V2 and V5. Brain Research, 493, 155-159.

RAUSCHECKER, J. P. (1995). Compensatory plasticity and sensory substitution in the cerebral cortex. Trends in Neurosciences, 18, 36-43.

Rauschecker, J. P., \& KNIEPERT, U. (1994). Auditory localization be- 
haviour in visually deprived cats. European Journal of Neuroscience, 6, 149-160.

RAUSCHECKER, J. P., \& KoRTE, M. (1993). Auditory compensation for early blindness in cat cerebral cortex. Journal of Neuroscience, $\mathbf{1 3}$, 4538-4548.

RECANZONE, G. H. (2000). Spatial processing in the auditory cortex of the macaque monkey. Proceedings of the National Academy of Sciences, 97, 11829-11835.

ReCANZONE, G. H., GuARD, D. C., \& Phan, M. L. (2000). Frequency and intensity response properties of single neurons in the auditory cortex of the behaving macaque monkey. Journal of Neurophysiology, 83, 2315-2331.

RoCKL AND, K. S. (1994). The organization of feedback connections from area V2 (18) to V1 (17). In A. Peters \& K. S. Rockland (Eds.), Primary visual cortex in primates (Vol. 10, pp. 261-299). New York: Plenum.

Rockland, K. S., \& OJima, H. (2003). Multisensory convergence in calcarine visual areas in macaque monkey. International Journal of Psychophysiology, 50, 19-26.

Rockland, K. S., \& VAN HoEsen, G. W. (1994). Direct temporaloccipital feedback connections to striate cortex (V1) in the macaque monkey. Cerebral Cortex, 4, 300-313.

Roder, B., Teder-Salejarvi, W., Sterr, A., Rosler, F., Hillyard, S. A., \& Neville, H. J. (1999). Improved auditory spatial tuning in blind humans. Nature, 400, 162-166.

Sadato, N., Pascual-Leone, A., Grafman, J., Ibanez, V., Deiber, M. P., Dold, G., \& Hallett, M. (1996). Activation of the primary visual cortex by Braille reading in blind subjects. Nature, $\mathbf{3 8 0}, 526-$ 528.

Salin, P. A., Girard, P., Kennedy, H., \& Bullier, J. (1992). Visuotopic organization of corticocortical connections in the visual system of the cat. Journal of Comparative Neurology, 320, 415-434.

Sanderson, K. J., Dreher, B., \& Gayer, N. (1991). Prosencephalic connections of striate and extrastriate areas of rat visual cortex. Experimental Brain Research, 85, 324-334.

Schmolesky, M. T., Wang, Y., HANes, D. P., Thompson, K. G., LeutGeb, S., Schall, J. D., \& Leventhal, A. G. (1998). Signal timing across the macaque visual system. Journal of Neurophysiology, $\mathbf{7 9}$, 3272-3278.

ScHROEDER, C. E., \& Foxe, J. J. (2002). The timing and laminar profile of converging inputs to multisensory areas of the macaque neocortex. Cognitive Brain Research, 14, 187-198.

Schroeder, C. E., Smiley, J., Fu, K. G., McGinnis, T., O’ConNELL, M. N., \& HACKeTt, T. A. (2003). Anatomical mechanisms and functional implications of multisensory convergence in early cortical processing. International Journal of Psychophysiology, 50, 5-17.

Somers, D. C., Dale, A. M., Seiffert, A. E., \& Tootell, R. B. (1999). Functional MRI reveals spatially specific attentional modulation in human primary visual cortex. Proceedings of the National Academy of Sciences, 96, 1663-1668.

STEIN, B. E. (1998). Neural mechanisms for synthesizing sensory information and producing adaptive behaviors. Experimental Brain Research, 123, 124-135.

StEIN, B. E., \& MEREDITH, M. A. (1993). The merging of the senses. Cambridge, MA: MIT Press.
Suzuki, W. A., \& Amaral, D. G. (2003). Perirhinal and parahippocampal cortices of the macaque monkey: Cytoarchitectonic and chemoarchitectonic organization. Journal of Comparative Neurology, 463, 67-91.

SYMONDS, L. L., \& Rosenquist, A. C. (1984). Laminar origins of visual corticocortical connections in the cat. Journal of Comparative Neurology, 229, 39-47.

Thompson, W. L., \& Kosslyn, S. M. (2000). Neural systems activated during visual memory imagery: A review and meta-analyses. In A. W. Toga \& J. C. Mazziotta (Eds.), Brain mapping: II. The systems (pp. 535-560). San Diego: Academic Press.

Tian, B., Reser, D., Durham, A., Kustov, A., \& Rauschecker, J. P. (2001). Functional specialization in rhesus monkey auditory cortex. Science, 292, 290-293.

Tolias, A. S., Smirnakis, S. M., Augath, M. A., Trinath, T., \& LoGOTHETIS, N. K. (2001). Motion processing in the macaque: Revisited with functional magnetic resonance imaging. Journal of Neuroscience, 21, 8594-8601.

Vanduffel, W., Payne, B. R., Lomber, S. G., \& Orban, G. A. (1997). Functional impact of cerebral connections. Proceedings of the $\mathrm{Na}$ tional Academy of Sciences, 94, 7617-7620.

Vanduffel, W., Tootell, R. B., \& Orban, G. A. (2000). Attentiondependent suppression of metabolic activity in the early stages of the macaque visual system. Cerebral Cortex, 10, 109-126.

Vezoli, J., Falchier, A., Jouve, B., Knoblauch, K., Young, M. A., \& Kennedy, H. (in press). Quantitative analysis of connectivity in the visual cortex: Extracting structure from function. The Neuroscientist.

Wallace, M. T., \& Stein, B. E. (1994). Cross-modal synthesis in the midbrain depends on input from cortex. Journal in Neurophysiology, 71, 429-432.

Wanet-Defalque, M. C., Veraart, C., De Volder, A., Metz, R., Michel, C., Dooms, G., \& Goffinet, A. (1988). High metabolic activity in the visual cortex of early blind human subjects. Brain Research, 446, 369-373.

Watson, R. T., Valenstein, E., Day, A., \& Heilman, K. M. (1994). Posterior neocortical systems subserving awareness and neglect: $\mathrm{Ne}-$ glect associated with superior temporal sulcus but not area 7 lesions. Archives of Neurology, 51, 1014-1021.

Weeks, R., Horwitz, B., Aziz-Sultan, A., Tian, B., Wessinger, C. M., Cohen, L. G., ET AL. (2000). A positron emission tomographic study of auditory localization in the congenitally blind. Journal of Neuroscience, 20, 2664-2672.

YAKA, R., YinON, U., \& WollBERG, Z. (1999). Auditory activation of cortical visual areas in cats after early visual deprivation. European Journal of Neuroscience, 11, 1301-1312.

ZEKI, S. (1978). Functional specialisation in the visual cortex of the rhesus monkey. Nature, 274, 423-428.

ZEKI, S. (1993). A vision of the brain. Oxford: Blackwell.

Zipser, K., LAmme, V. A., \& Schiller, P. H. (1996). Contextual modulation in primary visual cortex. Journal of Neuroscience, $\underline{\mathbf{1 6}}, \mathbf{7 3 7 6}$ 7389.

(Manuscript received October 15, 2003; revision accepted for publication May 7, 2004.) 